\section{An unforeseeable adverse event during ERCP}

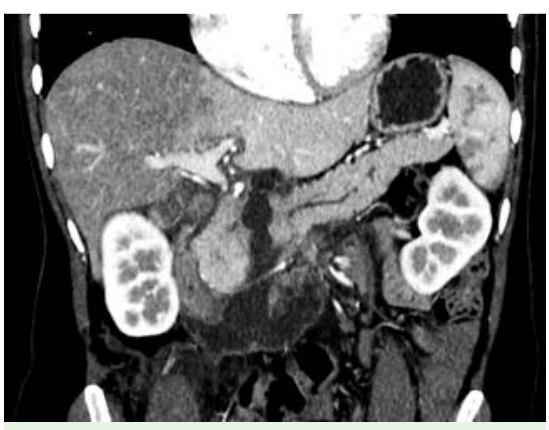

Fig. 1 Computed tomography (CT) scan showing complete transection of the pancreatic neck with disruption of the main pancreatic duct and a peripancreatic fluid collection.

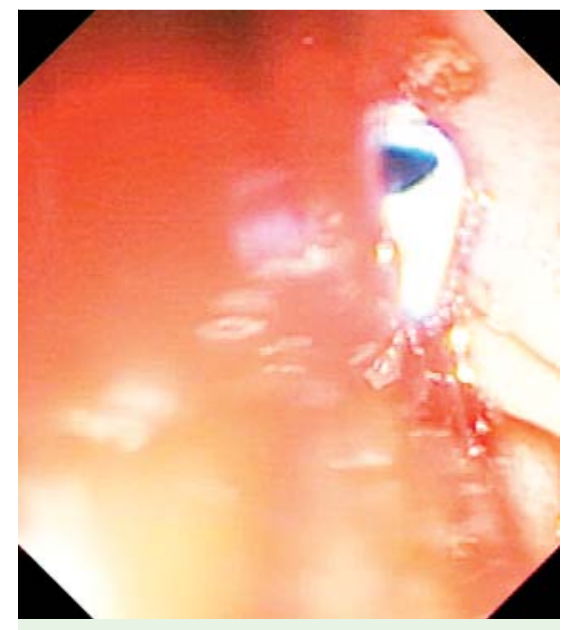

Fig. 3 View during a second endoscopic retrograde cholangiopancreatography (ERCP) a week later showing bleeding occurring immediately after stent deployment.
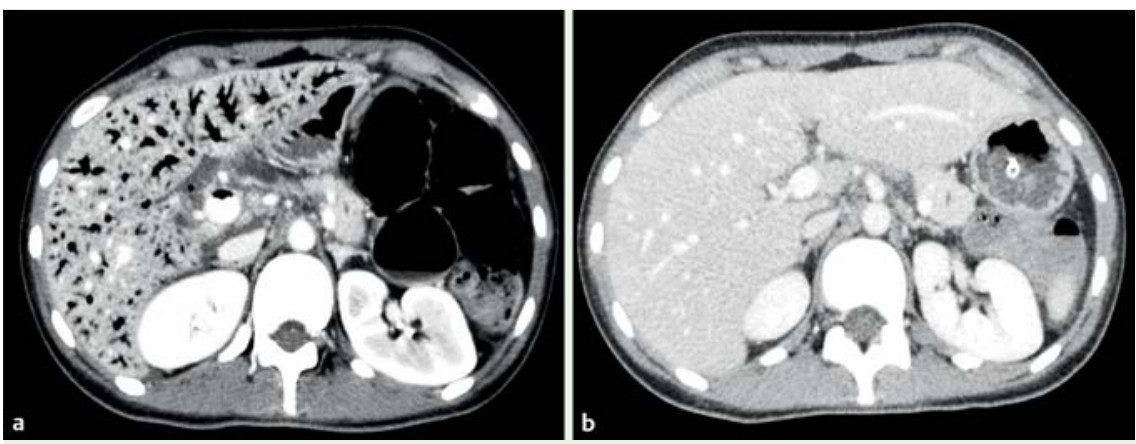

Fig. 5 Comparison between computed tomography (CT) scan images taken: a immediately after ERCP; $\mathbf{b}$ after the completion of hyperbaric oxygen therapy (HOT).
A 24-year-old previously healthy woman was involved in a bus accident in Nepal and sustained major blunt abdominal trauma with complete transection of the pancreatic neck. After 16 days of emergency stabilization in a local hospital, she was transferred to our center. Even though she appeared asymptomatic, abdominal imaging confirmed disconnected pancreatic duct syndrome with a $10-\mathrm{cm}$ fluid collection ( $\bullet$ Fig. $\mathbf{1}$ ). After multidisciplinary consultation, endoscopic transpapillary drainage was proposed $[1,2]$.

Following selective main pancreatic duct cannulation, the peripancreatic collection was opacified and a 7-Fr plastic stent $(5 \mathrm{~cm}$ in length) was successfully placed ( $\bullet$ Fig. 2). A week later, a second endoscopic retrograde cholangiopancreatography (ERCP) was performed to replace the stent with a larger one. During the procedure, a 0.031-inch guidewire was passed in the direction of the pancreatic tail and a $10-\mathrm{Fr}$ plastic stent $(5 \mathrm{~cm}$ in length) was inserted without prior opacification. Immediately after stent release, severe bleeding through the prosthesis was observed ( $\bullet$ Fig.3). An urgent computed tomography (CT) scan showed that the distal end of the pancreatic stent was inside the portal vein and there was massive portal air embolism ( $\bullet$ Fig. 4). The stent was immediately removed without further bleeding and hyperbaric oxygen therapy (HOT) was initiated. Complete air embolism resorption was achieved after three HOT sessions ( $\bullet$ Fig. $\mathbf{5}$ ).

Two months later, endoscopic-ultrasound (EUS)-guided pseudocyst drainage was successfully performed and the patient was discharged without any further intervention.

Air embolism is a rare but potentially lifethreatening complication of ERCP, which can occur with different pathophysiologic mechanisms [3], including portal vein cannulation $[4,5]$. In our case, a large plastic stent was inserted into the portal vein through the proximal pancreatic duct segment, establishing a direct connection between the portal vein and the intestinal lumen, which led to a massive portal air embolism. Portal thrombosis and sepsis are also possible serious sequelae of portal vein cannulation. The immediate removal of the stent and prompt initiation of HOT represent crucial steps to achieve a favorable outcome.

Endoscopy_UCTN_Code_CPL_1AK_2AC 
Laura Maggino ${ }^{1}$, Stefano Francesco Crinò $^{2}$, Laura Bernardoni ${ }^{2}$, Giovanni Marchegiani ${ }^{1}$, Giuseppe Malleo ${ }^{1}$, Roberto Salvia ${ }^{1}$, Armando Gabbrielli ${ }^{2}$

${ }^{1}$ Unit of Surgery B, Department of Surgery and Oncology, The Pancreas Institute, University of Verona Hospital Trust, Verona, Italy

2 Unit of Digestive Endoscopy, Department of Medicine, The Pancreas Institute, University of Verona Hospital Trust, Verona, Italy

\section{References}

1 Iacono C, Zicari M, Conci S et al. Management of pancreatic trauma: A pancreatic surgeon's point of view. Pancreatology 2016; 16: $302-308$

2 Hamidian Jahromi A, D'Agostino HR, Zibari $G B$ et al. Surgical versus nonsurgical management of traumatic major pancreatic duct transection: institutional experience and review of the literature. Pancreas 2013; 42: $76-87$

3 Kwon CI, Song SH, Hahm KB et al. Unusual complications related to endoscopic retrograde cholangiopancreatography and its endoscopic treatment. Clin Endosc 2013; 46: 251-259

4 Kalaitzakis E, Stern N, Sturgess R. Portal vein cannulation: An uncommon complication of endoscopic retrograde cholangiopancreatography. World J Gastroenterol 2011; 17: 5131-5132

5 Furuzono M, Hirata N, Saitou J et al. A rare complication during ERCP and sphincterotomy: placement of an endoscopic nasobiliary drainage tube in the portal vein. Gastrointest Endosc 2009; 70: 588 - 590
Bibliography

DoI http://dx.doi.org/

10.1055/s-0042-112992

Endoscopy 2016; 48: E278-E279

(c) Georg Thieme Verlag KG

Stuttgart · New York

ISSN 0013-726X

\section{Corresponding author}

\section{Armando Gabbrielli, MD}

Unit of Digestive Endoscopy

Department of Medicine,

The Pancreas Institute

G.B. Rossi Hospital,

University of Verona Hospital Trust

P.Le L.A. Scuro 10

37134 Verona

Italy

Fax: +39-045-8124743

armando.gabbrielli@univr.it 